\title{
Net Hata ve Noksan Hesabına Bakış: Seçilmiş Ülkelere Yönelik Analiz (1980-2018)
}

\author{
Net Errors and Omissions Account Overview: Analysis of Selected Countries
}

(1980-2018)

\section{Suna ŞAHIN ${ }^{1}$ (}

\section{Öz}

Ekonomi ile ilgili yayınlarda net hatalar ve noksanlar konusunda yani net hata ve eksikliklerin kökenleri ve bunların ödemeler dengesi üzerindeki etkileri hakkında çok fazla analiz yapılmamıştır. Ayrıca, net hata ve noksanların ne derece kabul edilebilir olduğunu gösteren açıkça tanımlanmış bir cevap da bulunmamaktadır. Her ülkenin kendine has özellikleri vardır ve ödemeler dengesi uyumsuzluklarının varlık nedenlerini genellemek bu açıdan oldukça zordur. Bu çalışma, seçilen ülkelerin (Singapur, Malezya, Amerika Birleşik Devletleri, Uruguay, Filipinler) 1980-2018 yıllarında ödemeler dengesi hesaplarındaki 'net hata ve noksan' hesabının makroekonomik değişkenlerle (GSYiH, ithalat ve ihracat rakamları olarak kabul edilen ticaret hacmi) olan ilişkisini araştırmaktadır. Çalışmaya ait veriler, Dünya Bankası ve IMF uluslararası finans istatistiklerinden alınmıştır ve seçilen ülkelerin yıllık verileri kullanıımıştır. Çalışmada, verilerin durağanlaştırılması sonrası, panel veri analizi tercih edilmiştir. Elde edilen sonuçlara göre ticaret hacmi net hata noksan üzerine negatif bir etki yaparken, GSYiH net hata noksanı pozitif yönde etkilemektedir. Tutarsızlıkların nedenleri genellikle bilinmemekle birlikte, bazı durumlarda istatistiklerin gözden geçirilmesini gerektiren açıklamalar daha sonra ortaya çıkmaktadır. Zamanlama boşluğu, yetersiz kapsam veya metodolojik sorunlar dengesizliklere neden olabilir. Net hata ve noksan hesabının varlığının nedeni yani kaynağının bulunmasıyla, ödemeler dengesi istatistiklerinin kalitesi daha da iyileştirilebilir. Veri kaynakları iyi seçilmeli ve sorunlar yaşanmaması adına bu konuda yasalar ve cezai politikalar net bir şekilde belirtilmelidir.

Anahtar Kelimeler: Uluslararası ticaret, Ödemeler dengesi, Denkleştirici kalemler, Net hata ve noksan, Panel veri analizi

Jel Sınıflaması: C33, F32, F40
'Dr. Öğretim Üyesi, İktisadi ve İdari Bilimler Fakültesi/ Uluslararası Ticaret ve Lojistik Bölümü, İstanbul-Türkiye

ORCID: S.Ş. 0000-0002-8241-739X

Sorumlu yazar/Corresponding author: Suna ŞAHIN,

İktisadi ve İdari Bilimler Fakültesi/ Uluslararası Ticaret ve Lojistik Bölümü, İstanbul-Türkiye E-posta/E-mail:

suna.sahin@yeniyuzyil.edu.tr

Başvuru/Submitted: 08.11.2021

Revizyon Talebi/Revision Requested: 01.12.2021

Son Revizyon/Last Revision Received: 24.12.2021

Kabul/Accepted: 10.01.2022

Atıf/Citation: Sahin, S. (2022). Net hata ve noksan hesabına bakış: seçilmiş ülkelere yönelik analiz (1980-2018). Iktisat Politikası Araştırmaları Dergisi - Journal of Economic Policy Researches, 9(1), 103-120.

https://doi.org/10.26650/JEPR1020460 


\begin{abstract}
Not many analyses have been conducted on net errors and omissions in publications on Economics which is relevant to the origins of net errors and omissions and their effects on the balance of payments. There is no clarified answer to indicate the degree to which errors and omissions are acceptable. Each country has its characteristics, and it is tough to generalize the reasons behind the balance of payment mismatches. This research intends to study the relationship between selected countries' (India, Singapore, Malaysia, United States, Uruguay, Philippines) balance of payment accounts 'net errors and Omissions' account of macroeconomic variables (GDP, trade volume considered as import and export figures) in the years of 1980-2018. The data for this study were collected from the World Bank and IMF international financial statistics and the selected countries' annual data. In the study, panel data analysis was preferred after stasis analysis of the data. According to the results obtained, while trade volüme harms net errors and omissions, the increases in GDP are being affected positively in that direction. The inconsistencies are often unknown, although in some cases, explanations that require a review of statistics emerge later. Timing gaps, insufficient coverage, or methodological issues can cause imbalances. By finding the reason for the existence of the net error and omissions account, that is, its source, the quality of the balance of payments statistics can be further improved. Data sources should be chosen well, and laws and penal policies should be clearly stated to avoid problems.
\end{abstract}

Keywords: International trade, Balance of payment, Balancing item, Net errors and omissions, Panel data analysis

Jel Classification: C33, F32, F40

\title{
EXTENDED ABSTRACT
}

Balance of payments statistics is considered an integral part of national accounts for most countries globally. The balance of payments account is essential in analyzing and forecasting the country's economic performance and in formulating economic policy, including monetary and exchange policy. Net errors and omissions are accounts that result from inconsistencies in the double-entry accounting system due to misrecorded or missing items. The net balance of errors and omissions constitutes the balancing item. The balancing element can be interpreted differently and its analytical content and meaning change accordingly. The sum of all transactions on the credit side must equal the sum of all transactions on the debit side (with a minus sign). Therefore, it is necessary to collect data as efficiently as possible, process it, and promptly present it to the user. Even the most precise and accurate data will not be helpful if provided too late because, as a result, there will be a specific difference between credit and debit.

Given that the principle of double-entry bookkeeping requires that these two sides be numerically equal, errors and omissions arise equal to the difference between credit and debit. Therefore, errors and omissions, as a balancing item of the balance of payments account, include all errors and omissions made in a given period when compiling balance of payments statistics. Net error and omission calculation have not been a subject of much attention, both in Turkey and in other countries, since it was thought that the errors and omissions in the balance of payments statement calculations would not be too significant. In 
this study, these countries were preferred because the net errors and omissions in the balance of payments table showed an increasing trend since 1980. In addition, it was chosen considering that the net errors and omissions, which are also stated as short-term capital inflows, have a positive effect on economic growth (the GDP figures, which are the economic growth indicators of the preferred countries, tend to increase each year). Whether there is a relationship between the "net errors and omissions in the balance of payments accounts and macroeconomic variables (GDP, trade volume considered as import and export figures) in 1980-2018, and if there is a relationship (positive/negative) with which variable. It has been tried to explain the empirical application it has shown. It requires introducing a compensatory entry known as net errors and omissions so that the sum of all international transactions in each country is equal to zero. The literature search shows relatively few studies on net errors and omissions or balancing elements. This study has concluded that the increase in imports and exports (trade volume) in selected countries harms net errors and omissions, while the increase in GDP positively affects net error omission in these countries. The inconsistencies are often unknown, although in some cases, explanations that require a review of statistics emerge later. Timing gaps, insufficient coverage, or methodological issues can cause imbalances. By finding the reason for the existence of the net error and omissions account, that is, its source, the quality of the balance of payments statistics can be further improved. Data sources should be chosen well, and laws and penal policies should be clearly stated to avoid problems. In addition, the movement of errors and omissions can be considered an essential indicator for those who direct the economic policy. In conclusion, it can be said that all these reasons clearly show that the calculation of net errors and omissions in the balance of payments is an economic indicator of the steps to be taken in general, not just in the field of statistics. 


\section{Giriş}

Ödemeler dengesi istatistikleri, dünyadaki çoğu ülke için ulusal hesapların ayrılmaz bir parçası olarak kabul edilmektedir. Ödemeler dengesi hesabı, ülkenin hem ekonomik performansını analiz ve tahmin etmede hem de para ve döviz politikası dahil olmak üzere ekonomi politikasını formüle etmek adına çok önemlidir. Ekonomik performansın ve refahın bir göstergesi olarak, ödemeler dengesi istatistiklerinin, ekonomi politikasının olası yönleri hakkında sinyaller verdiği kabul edilmektedir. Bir ekonomide belirli bir dönemde tüm ekonomik faaliyetlerin sistematiksel olarak kaydını gösteren ödemeler dengesi ve kalemleri birçok yönden de önemi olan bir ekonomik göstergedir. Ödemeler dengesi sonuçları aslında toplu olarak bireysel seçimlerinde sonucudur. Dolayısıyla ödemeler dengesi istatistikleri ve bunların güvenilirliği, kamu çıkarını ilgilendiren konuları da kapsamaktadır. Net hata ve noksan hesab1, ödemeler dengesi istatistiklerinin kalitesini veya güvenilirliğini doğrulamak için kullanılabilecek göstergelerden biridir. Net hatalar ve noksanlar, ödemeler dengesi istatistiklerinin muhasebeleştirilmesindeki bir tutarsızlığı ifade eder. Bu tutarsızlık, bazıları oldukça açık, bazıları ise daha gizli olan çeşitli nedenlerden kaynaklanmaktadır. Hatalar, unutmalar, eksikler, gecikmeler, eksik bilgi alma, kaçakçılık gibi durumlar nedeniyle otonom hesapların toplamı ile rezervler hareketleri hesabının toplamı mutlak değer olarak birbirini tutmayabilir. Böyle durumlar karşısında net hata ve noksan hesabının bir tarafında tek kalem olarak dönem sonu itibariyle kayıt düşülür.

Ödemeler dengesi tablosu hesaplarında yapılan hata ve noksanlıkların çok büyük olmayacağının düşünülmesinden kaynaklı olarak, net hata ve noksan hesabı gerek Türkiye'de gerekse diğer ülkelerde çok fazla ilgi gösterilen bir konu olmamıştır. Yapılan bu çalışmada ödemeler dengesi tablosundaki net hata ve noksan değerleri 1980 yılından itibaren giderek artış eğilimi gösterdiği için bu ülkeler tercih edilmiştir. Bunun yanı sıra kısa vadeli sermaye girişi olarak da belirtilen net hata ve noksanların ekonomik büyüme üzerindeki pozitif etkisinin olduğu (tercih edilen ülkelerin ekonomik büyüme göstergesi olan GSYİH rakamlarının her geçen yıl artış eğiliminde olması) düşünülerek seçilmiştir. 1980-2018 yıllarında ödemeler dengesi hesaplarındaki 'net hata ve noksan' hesabının makroekonomik değişkenlerle (GSYİH, ithalat ve ihracat artışları toplamını oluşturan ticaret hacmi) ilişkisinin olup olmadığı ve eğer var ise ilişkinin hangi değişkenle ne yönde (pozitif/negatif) bir etki gösterdiği ampirik uygulama ile açıklanmaya çalışılmıştır.

\section{2. Ödemeler dengesi istatistiklerinde net hata ve noksana bakış}

Ödemeler dengesinin çeşitli hesaplarının dengelenmesi gerekmesine rağmen, uygulamada dengesizlikler kaynak verilerdeki ve derlemedeki kusurlardan kaynaklanmaktadır. Mali hesaptaki net bakiyeden cari ve sermaye hesabından türetilen ilgili 
kalemin çıkarılmasıyla lehesaplanan bu tür dengesizlikler, net hata ve noksan olarak adlandırılır (Jellema, Pastoris ve Aguilar 2020, s.9). Diğer bir ifadeyle kaynak verilerdeki ve derleme sistemlerindeki kusurlar nedeniyle dengesizlikler ortaya çıkarsa, net hatalar ve eksiklikler mevcuttur. Net hatalar ve noksanların boyutu, yönü ve kalıcılığının önemi bu kalemin, ödemeler dengesinin en önemli göstergelerinden olduğu belirtilebilir.

Uluslararası Para Fonu (IMF) tarafından düzenlenen ödemeler dengesi kılavuzunda belirtildiği üzere, ödemeler dengesi 'belirli bir zaman dilimi için bir ekonominin dünyanın geri kalanıyla olan ekonomik işlemlerini sistematik olarak özetleyen istatistiksel bir ifadedir' (International Monetary Fund, 1993, s.6). Net hata ve noksanlar, 1948 y1l itibariyle ortaya çıkan ödemeler dengesi hesaplarının önemli bir parçasıdır. Net hata ve noksanlara, sadece hesapların denge unsuru olarak işlev gördüğü için ilk başlarda pek dikkat edilmemiştir (Kristinsson, 2016, s.10). Ödemeler dengesindeki tutarsızlıkları araştırmaya yönelik ilk büyük girişim, IMF tarafından desteklenen ve 1987' de yayınlanan Dünya Cari Hesap Uyuşmazlığı Raporudur (IMF,1987).

Ödemeler dengesi istatistiklerindeki hatalar ve noksanlar, reel olarak ölçülen tasarrufların (yani cari hesap bakiyesi ve sermaye dengesi) mali denge istatistiklerinde ölçülen mali akışların büyüklüğüne karşılık gelmemesi durumunda ortaya çıkar (Blomberg, Forss ve Karlsson, 2003, s.43). Cari hesap bakiyesi ve sermaye bakiyesi, tüm işlemler doğru bir şekilde kaydedilmişse, ters yöndeki finansal akışın büyüklüğüne eşit olmalıdır. Diğer bir deyişle, ödemeler dengesi verileri çift girişli defter tutma ilkesine dayanmaktadır. Cari ve sermaye hesaplarına ilişkin verilerin farklı kurumlar tarafından oluşturulması ve yine farklı kurumlar tarafından edinilmesi beraberinde birtakım eksiklikleri ve gecikmeleri getirmektedir. Dolayısıyla cari hesap, sermaye hesabı ve resmi döviz hareketleri toplamı pratikte sıfıra eşit olmamaktadır. Bu durum ödemeler dengesinde net hata ve noksan diye nitelendirilir (Ünsal, 2005, s.446). Net hata ve noksan, çift girişli muhasebe sisteminde yanlış kaydedilmiş veya eksik kalemlerden kaynaklanan tutarsızlıklardan kaynaklanan hesaplardır. Kısacası ödemeler dengesi istatistiklerindeki ölçüm hataları ve diğer eksikliklere karşı bir denge oluşturmak amacıyla, işlemlerin toplamının sıfır olmasını sağlamak için özel bir bilanço kalemi (hatalar ve noksanlar) getirilmiştir. Hatalar ve eksikler, istatistiksel tutarsızlık olarak bilinir ve bir ödeme dengesindeki fazla veya eksik beyanları dengelemeyi amaçlar (Adekunle, 2012, s.307).

\section{Net hata ve noksanın gerekliliği}

Veri toplama ve işlemenin lojistiği ve karmaşıklığı, uygulamada, işlemlerin hatalı olarak kaydedildiğini ve bazı işlemlerin hiç kaydedilmediğini (noksan) gösterir. Diğer bir ifadeyle hatalar işlemlerin yanlış kaydedildiği anlamına gelirken, noksan ise işlemlerin hiç kaydedilmediği anlamına gelir. Çoğu tartışmada, hatalar ve noksanlar öğeleri arasında net 
bir ayrım yapılmaz, bu nedenle terim toplu bir terim olarak kullanılır (Kristinsson, 2016, s.9). Normal şartlar altında, tüm uluslararası işlemlerin doğru, düzgün ve önemli bir zaman gecikmesi veya raporlama uygulamalarında farklılıklar olmaksızın kaydedilmesi durumunda, net hata ve noksanın kendi başına hiçbir ek bilgi taşımadığı varsayılır. Ancak hem gelişmiş hem de gelişmekte olan ülkelerden gelen tarihsel deneyim ve anekdotsal kanıtlar durumun her zaman böyle olmayabileceğini göstermiştir (Siranova, Tiruneh, ve Fisera 2020, s. 2).

Net hata ve noksan bakiyesi, dengeleme kalemini oluşturur. Dengeleme unsuru farklı şekillerde yorumlanabilir ve analitik içeriği ve anlamı da buna göre değişir. Alacak tarafındaki tüm işlemlerin toplamı, borç tarafındaki tüm işlemlerin toplamına (ters işaretli) eşit olmalıdır. Bu nedenle, bu kuralın tam anlamıyla uygulanabilmesi için aşağıdakiler gerekir (Kilibarda, 2013, s.8);

Her işlem iki kez kayıt altına alınır; bir kez alacak tarafında ve ikinci kez borç tarafında, her iki tarafın da eşleşmesi gerekir.

$>$ Her işlemin değeri her iki tarafta da aynı olmalıdır.

$>$ İşlem aynı anda her iki tarafa da kaydedilmelidir.

İlk bakışta çok basit olan yukarıdaki bu üç kural karşılanırsa, alacak tarafı ile borç tarafı arasında bir fark olmayacak, yani alacak toplamı borç toplamına eşit olacaktır. Uygulamada, her şeyden önce, aynı anda tamamen dahil edilemeyen veya dahil edilmeyen veya aynı şekilde ölçülemeyen çok sayıda işlem nedeniyle her iki tarafta eşit değildir. Verileri mümkün olduğunca verimli bir şekilde toplamak, işlemek ve zamanında kullanıcısına sunmak gerekir. En kesin ve doğru veriler bile çok geç sağlanırsa yararlı olmaz. Sonuç olarak, alacak ve borç arasında belirli bir fark oluşur. Çift girişli defter tutma ilkesinin bu iki tarafın sayısal olarak eşit olmasını gerektirdiği göz önüne alındığında, alacak ve borç arasındaki farka eşit olan hatalar ve noksanlar durumu ortaya çıkar. Dolayısıyla hatalar ve noksanlar, ödemeler dengesi hesabının dengeleme kalemi olarak, ödemeler dengesi istatistiklerini derlerken belirli bir zaman diliminde yapılan tüm hata ve noksanları içerir. Net hata ve noksan hesabı gerek reel sektör ve gerekse de finans sektörünün kayıtsız ve eksik bilgilerini ortaya çıkarabilir (Ding \& Tang, 2017, s.2758). Küreselleşme süreçleri nedeniyle ödemeler dengesi istatistikleri giderek daha fazla önem kazanmaktadır. Öte yandan ticaret ve sermaye akışının serbestleştirilmesi veri kalitesini olumsuz etkileyebilir (Bazı işlemler yanlış olarak kaydedilebilir veya hiç kaydedilmeyebilir). Tüm bu tutarsızlıklar, net hata ve noksan adlı dengeleme kalemi olarak ödemeler dengesine dahil edilecektir (Bieganska, 2016, s.186).

Hata ve noksanlığı yaratan ölçüm hataları aşağıdaki açılardan ele alınabilir (Blomberg ve ark., 2003, s.44): 
Kapsam hataları: Yurtdışında işi olan tüm operatörler anketlere dahil edilmemiştir. Alternatif olarak, yurtdışındaki işlemlerinin sadece bir kısmı tescil edilmiştir.

> Ölçüm hataları (değerlendirme hataları): Tanımlar, raporlama kuruluşlarından gelen bilgiler ve para birimlerinin çevrilmesinin yanlış olması (örneğin, döviz kuru dalgalanmaları) nedeniyle kaydedilen değerler.

> Zaman uyumsuzlukları: İşlemler yanlış süre için raporlanabilir. İhraç edilmiş olan malın gidiş tarihi ile ihraç edilen mal karşılığında alınacak olan paranın gelişi farklı dönemlerde olabilir.

Sınır ötesi işlem faaliyeti perspektifinden dengeleme kaleminin ortaya çıkışının esas nedeni, herhangi bir verili işleme ilişkin kayıtların temelde farklı kaynaklardan sağlanmasındandır. Alternatif olarak, net ulusal tasarruf, cari hesap dengesi ve ulusal servet oluşumu arasındaki ilişkinin tanınması, dengeleme kaleminin ulusal servet birikim sürecinin belgelenmesindeki hataların belirtisi olabileceğini düşündürmektedir (Fausten \& Brooks, 1996, s.1303).

Committeri'e (2000, s.24) göre, fiyat ve döviz kurlarındaki oynaklık hesapların doğruluğunu etkilediğinden ödemeler dengesi ve uluslararası yatırım pozisyonu derlenirken finansal bilgi miktarının artırılmasını savunur, yani her dönem için sabit fiyat veya döviz kurlarının kullanılması hatalara neden olur ve diğer kaynaklarla mutabakatı zorlaştırır. Kısa vadeli sermaye girişleri olarak da adlandırılan net hata ve noksan hesabı, özellikle gelişmekte olan ülkeler için ekonomik büyümeyi hızlandırırken (örneğin, Malezya), bazen de finansal krizlere de sebebiyet vermektedir (Alagöz, 2014, s.887).

\section{Literatür araştırması}

Dünya ekonomisinin değişim sürecindeki hızı özellikle 1980'li yıllarda başlayan finansal liberalizasyon politikasına geçişledir. Bu politikayı uygulamaya çalışan sanayileşmiş (gelişmiş) veya gelişmekte olan ülkelerin birçoğu mali küreselleşmeye bağlı olarak sermaye hareketliliğinin önündeki engelleri kaldırmak ya da yerli ve yabancı yatırımcılara bankacılık sektörünü açmak gibi birtakım reformları uygulamaya koymuşlardır (Kar \& Kara, 2004, s. 18). Bu süreçte sanayileşmiş ülkeler (örneğin; ABD gibi), kendi finansal piyasalarını liberalleştirmek adına ekonomi politikaları uygularken onları gelişmekte olan ülkeler de takip etmiştir (TCMB, 2002, s.10). Küresel çapta ülkelerin süreç dışında kalmak istememeleri bunun yanısıra ekonomik büyüme ve kalkınma istekleri serbestleştirmeyi seçmelerindeki nedenler arasındadır. Ancak söz konusu dönemde serbestleştirmeyi seçen ülkelerin birçoğu hem mali hem de parasal krizlerle karşı karşıya kalmıştır. Örneğin, Filipinler (1981 krizi), Malezya (1985,1997 krizleri), Singapur (1997 krizi) ve Uruguay (1981 krizi) ciddi krizler 
yaşamışlardır (Duman, 2004, s.42-43). Bu krizler ülkelerin birçok makroekonomik parametresinin değişimine neden olmuştur. Finansal liberalizasyonun ödemeler bilançosunda meydana getirdiği etki alanları döviz kuru, dış ticaret (ithalat-ihracat verileri), doğrudan sermaye yatırımları ve dolaylı olarak etkilenen net hata ve noksan kanalıdır. Net hata ve noksan kaleminin bu açıdan sermaye giriş ve çıkışlarına bağlı olarak kontrollerin kaldırılmasıyla kayıt dışı sermaye giriş ve çıkışları ile ortaya çıktığı belirtilebilir. Çalışmada seçilen ülkelerin ortak özelliği 1980 yılından sonra serbestleşme politikalarını seçen gelişmekte olan ülkeler olmasındandır. Buna ilaveten sanayileşmiş ülke konumundaki Amerika Birleşik Devletleri ise hem ticari hem de sermaye hareketliliği serbestleştirmesinde ülkeleri destekleyici ve finansal piyasalarını serbestleştirme politikası uygulamasından dolayı seçilmiştir. Ayrıca seçilen ülkelerin ortak özelliği net hata noksan kalemi verilerinin özellikle kriz dönemlerinde büyük negatif bakiye vermesindedir.

Her bir ülkede tüm uluslararası işlemlerin toplamının sıfıra eşit olması için, net hatalar ve noksanlar olarak bilinen bir telafi edici girişin varlığına ihtiyaç doğar (Cencini, 2005). Literatür araştırması, net hata ve noksan veya dengeleme öğeleri üzerine yapılmış çalışmaların nispeten az olduğunu göstermektedir. Net hata ve noksan kalemine ilişkin literatürdeki temel tartışma alanlarından birisi net hata noksan kaleminin etkileyen faktörler diğeri de net hata noksan kaleminin sürdürülebilirliğidir. Sürdürülebilirlik üzerine çalışmalar daha fazladır. Bu nedenle bu çalışma ile literatür de daha az çalışması yapılan net hata ve noksanı etkileyen faktörler hususundaki çalışmalara katkıda bulunmak amaçlanmıştır. Net hata ve noksan kaleminin nedenleri üzerindeki çalışmalar şunlardır: Duffy ve Renton (1971), Tombazos (2003), Blomberg ve ark. (2003), Fausten ve Pickett (2004), Lin ve Wang (2009), Vuksic (2009) ve Tang (2006), Tang (2017), Taştan (2015), Siranova ve Tiruneh (2018), Siranova ve ark. (2021), Keşap ve Sandalcılar (2021). Kronolojik olarak sıralanan bu konudaki sınırlı çalışmalara yönelik açıklamalara aşağıda değinilmiştir.

Net hata ve noksan kaleminin nedenleri üzerindeki çalışmalar arasındaki Duffy ve Renton (1971) çalışmasını Birleşik Krallık üzerine yapmışlar ve analizde otonom hesaplar içerisinden olası 11 değişkenin net hata ve noksan ile etkileşimine odaklanılmıştır. 1958-1967 dönemini kapsayan çalışmada kullanılan açıklayıcı değişkenler, ihracat ve yeniden ihracat toplamı, ithalat, hizmetler sektörü denge değeri, yurt dışına yapılan net özel yatırımlar, ülkeye yapılan net özel yatırımlar, dış yükümlülüklerdeki net değişim, diğer sermaye (spesifik bir başlıkta yer almayan sermaye), para akışı dengesi, spot döviz kuru (dolar üzerinden), Birleşik Krallık ile Birleşik Devletler arasındaki faiz oranı farkı ve zamanlama hatalarını göstermesi adına net hata ve noksansın gecikmeli değeri şeklindedir. Açıklayıcı değişkenlerden 4 grup oluşturularak öncelikle temel bileşenler analizi ile varyans oranları bulunmuş, sonrasında en küçük kareler (EKK) yöntemi ile analiz gerçekleştirilmiştir. Analizden birkaç temel sonuca ulaşılmıştır. Öncelikle zamanlama hatalarının önemli bir sebep olduğu ortaya koyulmaktadır. İkinci olarak, 
dış ticaret ve özel yatırımlarla net hata ve noksan hesabının ilişkili olduğu vurgulanmaktadır. Diğer taraftan, kısa dönemli para hareketlerinin net hata ve noksanı etkilediği sonucuna varılmaktadır.

Tombazos (2003) çalışmasında Avusturalya'yı örnek almıştır. Net hata ve noksanın politika açısından da önemli araştırma konusu olduğunu belirtmiştir. Net hata ve noksan hesabının mallar, hizmetler ve finansal piyasalar gibi piyasalar için gizli bilgiler içerdiğini bu nedenle üzerinde önemle durulması gerektiğini belirtmiştir.

Blomberg ve ark. (2003) çalışmasında İsveç ülkesini ele alarak ödemeler dengesi açısından ekonomik ve finansal istatistiklerin kullanım ve yorumlanmasında hata ve eksikliklerin yarattığ belirsizliğin etkileri üzerinde durulmuştur. Sonuçlarda, İsveç için hanehalkının yurt dışındaki doğrudan yatırımlarının istatistiklerde yer almamasının net hata ve noksanlıklara yol açtığ belirtilmiştir. Ödemeler dengesindeki hata ve noksan kalemi GSYİH, GSMH ve net diş yatırımlar ile ilişkilidir. Akımların ve dalgalanmalarının yorumlanmasında en çok etkilenen mali dengedir. Diğer bir sonuçta, ödemeler dengesindeki hata ve noksan kaleminin bir bütün olarak reel ekonomideki gelişmelerin boyutu hakkında da yanlış yorumlamalara neden olabileceğidir.

Fausten ve Pickett (2004) çalışmasında, Avustralya'nın sınır ötesi işlem kayıtlarının istatistiksel özelliklerinin araştırarak rapor edilen durumun hata ve noksanları nasıl etkilediğine bakılmıştır. Zaman serilerinin düzeyinde, trendinde ve/veya varyansında çoklu yapısal kırılmaları tespit etmek için Wang ve Zivot (2000) tarafından geliştirilen Bayes yöntemlerini kullanmışlardır. Çalışmanın sonuçlarında, finans sektörü işlemlerinin, ödemeler dengesi sonuçlarının yanlış raporlanmasına neden olduğu, sınır ötesi işlemlerin ölçülen gerçek büyüklüklerinin yansıtılmadığı ve bütün bunların dengeleme kalemindeki istikrarsızlığı yansıttı̆̆ı sonucuna varılmıştır.

Tang (2006) çalışmasında Japonya'da ekonomik açıklık değişkenini ele alarak bunun dengeleme kalemi üzerindeki etkisini araştırmıştır. Çalışmanın sonucu ekonomik açıklığın Japonya'nın dengeleme kalemini etkilediğini göstermiştir.

Lin ve Wang (2009) çalışmasında ise, zamanlama hataları, sermaye akımları ve dışa açıklığın, net hata ve noksan ile ilişkisini dört ülke özelinde (Norveç, İsveç, Filipinler ve Güney Afrika) incelenmektedir. Elde edilen bulgulara göre, Norveç’te dışa açıklık, İsveç’te mevsimsel unsurlar öne çıkmakta; Filipinler için kararlı sonuçlara ulaşılamamakla birlikte bu durumun politik sorunlarla ilişkili olabileceği düşünülmekte; Güney Afrika'da ise tüm değişkenlerin net hata ve noksan ile ilişkili olduğu sonucuna varılmaktadır.

Vuksic (2009) çalışmasında, Hırvatistan üzerine araştırma yapmıştır. Hırvatistan Ulusal Bankasından alınan veriler ve raporlara göre değerlendirmeler yapan Vuksic'e göre, yabancı 
turistlerin harcamalarından elde edilen, rapor edilmemiş veya eksik beyan edilen gelirin yanı sıra kayıt dışı ekonomide elde edilen gelir için vergi toplama mekanizmasındaki boşluklar nedeniyle negatif bir net hata ve noksan değeriyle sonuçlanan çok büyük miktarda kayıt dış1 mevsimlik yabancı nakit fazlası birikimi vardır.

Tang (2017) çalışmasında, Avusturalya üzerine araştırma yapmıştır. Bu çalışma, ödemeler dengesi hesaplarındaki 'net hata ve noksan' davranışının makroekonomik belirleyicilerini araştırmaktadır. Bu çalışma GSYİH, faiz oranı ve döviz kurunun Avustralya'daki "net hata ve noksanları" açıklayan önemli faktörler olduğunu ortaya koymaktadır. Var analizi, nedensellik testleri uygulanmıştır. Tang (2007) göre, dengeleme kalemi ekonomik bir değişken değildir ve bilgi kaybı nedeniyle, dengeleme öğesinin gerçek kalıpları gerçek veriler kullanılarak yakalanamamaktadır. $\mathrm{Bu}$ nedenle, analiz nominal verilerle yapılmalıdır.

Taştan (2015) çalışmasında, 33 OECD üyesi ülke üzerinde araştırmasını yapmıştır. Bu çalışmanın amacı, OECD üyesi ülkelerde ödemeler dengesi kaleminin sürdürülebilirliğini araştırmaktır. Her ülkenin örnekleme periyodu, verilerin mevcudiyetine bağlıdır ve analizde Fourier birim kök testleri kullanılmaktadır. Ampirik analize göre ödemeler dengesi kalemi Avustralya, Kanada, Macaristan, Norveç, İsviçre ve Amerika Birleşik Devletleri için sürdürülebilirdir. Sonuçlar ayrıca, doğrusal olmamanın ödemeler dengesi kalemi için temel bir özellik olduğunu göstermektedir.

Siranova ve Tiruneh (2018) çalışmalarında Slovakya örneği üzerinde durmuşlar ve net hata ve noksanın zaman serilerinde belirgin bir gerilemenin gözlemlendiği 2008-2014 alt dönemine vurgu yaparak, 1997-2014 döneminde Slovakya'nın net hata ve noksanının belirleyicilerini ampirik olarak araştırmışlardır. 1997-2014 dönem aralığı için sermaye akımlarının, mal ticaretinin, doğrudan yatırımlar ve hizmetler ihracatının net hata ve noksan ile ilişkisine bakmışlardır. Sonuçlarda, mal ticareti dışındaki değişkenlerin net hata ve noksan ile ilişkili olduğu sonucuna varılmıştır.

Keşap ve Sandalcılar (2021) çalışmasında, Türkiye için 2008:1-2020:3 dönem aralığında net hata ve noksan hesabının belirleyicileri araştırılmıştır. Çalışma, ARDL eşbütünleşme yöntemiyle analiz edilmektedir. Analize, açıklayıcı değişkenler olarak bavul ticareti, turizm gelirleri, ihracat rakamları ve yurt içi yerleşiklerin yurt dışında tuttukları mevduatları dâhil edilmiştir. Elde edilen bulgular, değişkenler arasında eşbütünleşme ilişkisinin olduğunu göstermiştir. Diğer taraftan, net hata ve noksan hesabını açıklayan en önemli değişkenin, yurt içi yerleşiklerin yurt dışı mevduatları olduğu sonucuna varılmıştır.

Siranova ve ark. (2021) çalışmasında 2006-2007 yılları arasında seçtiği 31 Avrupa ülkesi için net hata ve noksan hesabının seçtiği değişken olan kayıt dışı sermaye akışlarıyla olan 
ilişkisini araştırmıştır. Sonuçlarında ise seçilen değişkenle net hata ve noksan hesabının doğrudan ilişkili olduğunu tespit etmiştir.

Çalışmalarda seçilen ülkeler üzerindeki araştırmalar dengeleme kaleminin ortaya çıkmasına neden olan hususların belirlenen değişkenler ile ilişkisinin ülke bazında farklılıklar gösterdiğine vurgu yapmıştır. Dengeleme kalemi olan net hata ve noksan hesabının iki nedenle açıklanması gerekir (Duff ve Renton, 1971, s.448). Birincisi, cari ve sermaye hesabının genel dengedeki hareketlerle karşılaştırıldığında, varyansı ve büyüklüğü önemlidir. İkincisi, dengeleme kaleminin genel ve parasal bakiye tahminlerinin toplamına eşit olduğundan bir yanda cari ve sermaye hesabı üzerindeki denge tahminleri ile diğer yanda parasal hareketler tahminleri arasında faydalı bir karşılaştırma yapılmasına yardımcı olur. Dengeleme kaleminin kaynakları hakkında kesin bir kanıt yoktur. Dolayısıyla dengeleme kalemine yönelik olarak standart bir oran ya da miktardan söz edilemez. Buna karşın bu miktarın boyutu sürekli aynı yönde gelişiyor olması kayıtların, ölçümlerin, hesapların ve anketlerin doğru olmadığı yönünde kuşkuları artırır.

\section{Ekonometrik analiz}

Çalışmaya ait veriler, Dünya Bankası ve IMF uluslararası finans istatistiklerinden alınmıştır. Seçilen ülkeler Singapur, Malezya, Amerika Birleşik Devletleri, Uruguay, Filipinler'dir. Çalışmada seçilen ülkelerin yıllık verileri kullanılmıştır. Çünkü üç aylık veriler, zamanlama gecikmeleri üzerinde güçlü bir etkiye sahip olabilir; bu, yıllık rakamlarda bu gecikmelerin çoğunun ortadan kaldırılabileceği anlamına gelir (Barseghyan \& Davtyan, 2018).

Panel veri analizi yardımı ile incelenecek olan modele geçmeden önce, modelde kullanılacak olan değişkenlere ait özet istatistikler aşağıdaki tablo 1'de verilmiştir. Modelde; net hata noksan (nhn), ticaret hacmi [ihracat(x)+ithalat(m)], gayri safi yurt içi hasıla (ln_gdp), kullanılmıştır.

Tablo 1: Değişkenlere Ait Tanımlayıcı istatistikler

\begin{tabular}{lccccc}
\hline Değişken & Obs & Mean & Std. Dev. & Min & Max \\
\hline nhn & 195 & 2.179953 & 25.15725 & -77.9571 & 148.091 \\
ln_xm & 195 & 25.0092 & 2.039409 & 20.95207 & 28.56294 \\
ln_gdp & 195 & 26.19174 & 2.091088 & 23.58157 & 30.51922 \\
\hline
\end{tabular}

İktisadi değişkenlerin genel itibariyle trend içermelerinden dolayı birbirleri üzerinde var olmayan ilişkileri göstermeleri, yüksek R2 değerleri vermeleri sahte regresyon olarak adlandırılmaktadır. Dolayısıyla bulunan sonuçların sahte mi yoksa gerçekten anlamlı mı olduğunun kararı önem kazanmaktadır. Bu karar ise durağanlık testleri ile verilmektedir (Gujarati \& Porter, 2012, s.737). Modelde kullanılacak olan değişkenlere ait grafikler aşağıda verilmiştir. 
Panel veri ekonometrisinde birimler arası korelasyonun varlığına göre çeşitli testler bulunmaktadır. Eğer seride birimler arası korelasyon mevcutsa ikinci kuşak panel birim kök testleri önerilmiştir (Yerdelen Tatoğlu, 2012, s.105). Panel veri setinde birimler arası korelasyonun testi için Pesaran (2004) CD testi tercih edilmiştir. Teste ait çıktı aşağıda verilmiştir.

\section{Grafik 1. Değişkenlere Ait Grafikler}

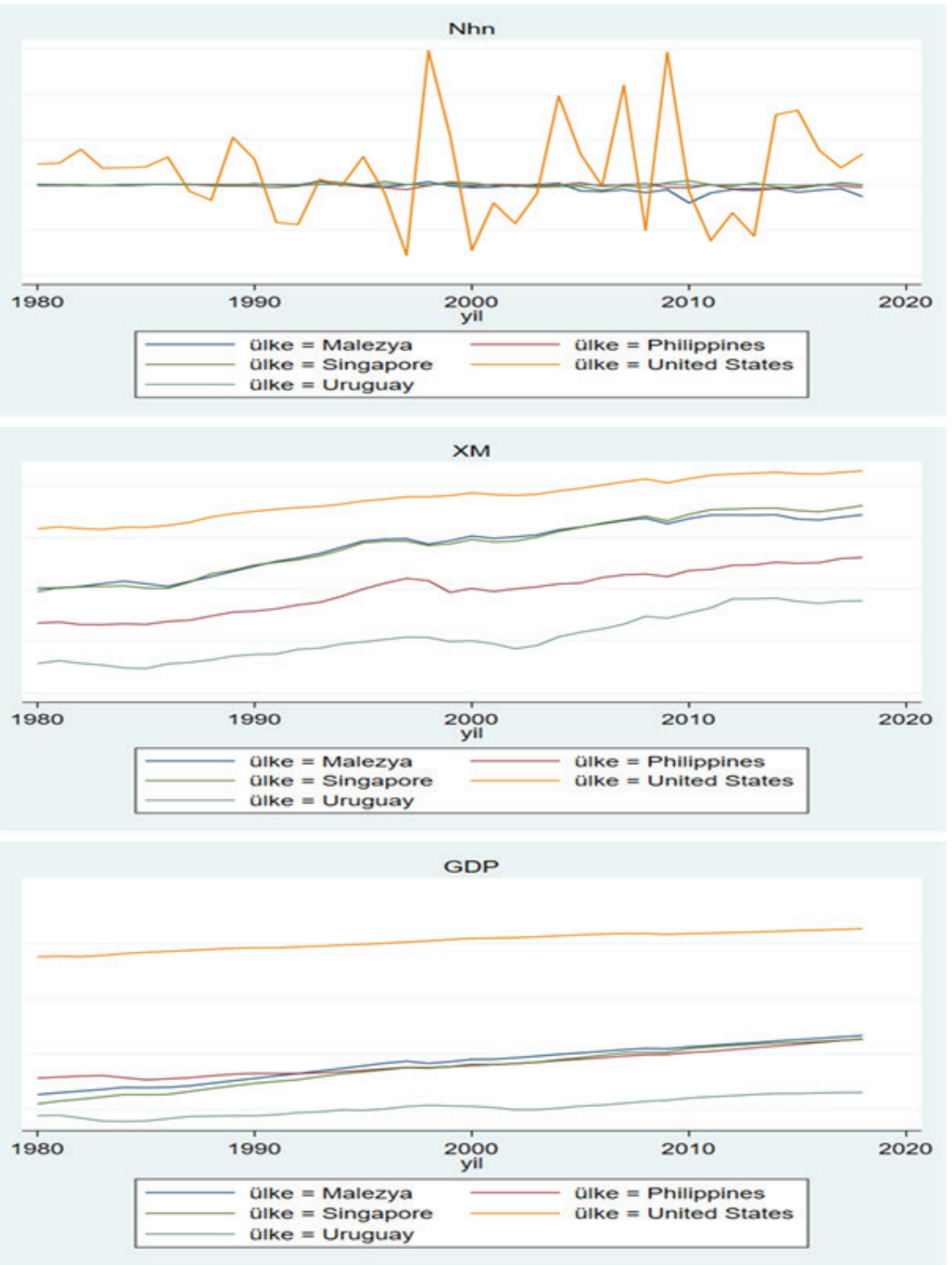


Tablo 2 : Pesaran CD Testi Çıktı Sonuçları

\begin{tabular}{lcccc}
\hline Değişken & CD-test & p-value & corr & abs(corr) \\
\hline nhn & 1.14 & 0.255 & 0.058 & 0.107 \\
ln_xm* & 19.16 & 0.0000 & 0.970 & 0.970 \\
ln_gdp* & 19.01 & 0.000 & 0.963 & 0.963 \\
\hline
\end{tabular}

*: Birimler arası korelasyon vardır. İkinci kuşak panel birim kök testleri kullanılacaktır.

Yukarıda verilen çıktıda nhn olarak ifade edilmiş olan net hata noksan değişkeni için birimler arası korelasyon olmadığını ifade eden $\mathrm{H}_{0}$ hipotezi reddedilememiştir, durağanlık testi 1. kuşak panel birim kök testleri yardımıyla yapılacaktır. Ticaret hacmini ve GDP'yi temsilen kullanılan $\ln \_x m$ ve $\ln \_g d p$ değişkenlerinde ise $\mathrm{H}_{0}$ hipotezi reddedilmiştir. Ticaret hacmi ve GDP değişkenlerinde birimler arası korelasyonun olması sebebiyle durağanlığın sınanmasında 2. kuşak birim kök testlerinden yararlanılacaktır.

Durağanlık sınaması için Levin, Lin ve Chu tarafından ortaya koyulan panel birim kök testi kullanılmıştır. Levin, Lin ve Chu (LLC) panel birim kök testinde $\mathrm{H}_{0}$ hipotezi: birimler birim kök içermektedir, şeklinde kurulur. Alternatif hipotez ise birimler durăgandır şeklindedir. CD testi sonuçlarına göre birimler arası korelasyona sahip olan değişkenlerin durağanlığg, bu bağımlılığın etkisinin azaltılabilmesi amacıyla, yatay kesit ortalamalarından fark alınarak araştırılacaktır. Durağanlık sınamasına ilişkin çıktılar aşağıdaki tablo 3'de verilmiştir.

Tablo 3: Levin, Lin ve Chu (LLC) Panel Birim Kök Testi

\begin{tabular}{lccc}
\hline SEVIYE & & & \\
\hline Değişken & Unadjusted $\mathbf{t}$ & Adjusted $\mathbf{t}$ & $\mathbf{P}$ \\
\hline nhn & -9.3746 & -7.2204 & $0.0000^{* *}$ \\
ln_xm* & -3.8735 & -1.8956 & $0.0290^{* *}$ \\
ln_gdp* & -4.8236 & -3.8887 & $0.0001^{* *}$ \\
\hline
\end{tabular}

*Yatay kesit ortalamalarından fark alınmış serileri temsil etmektedir.

**Test istatistiğinin \%1 önem düzeyinde anlamlılığını temsil etmektedir.

Yukarıda görüleceği üzere tüm değişkenler seviye değerlerinde durağandır. Durağanlık sınaması akaike bilgi kriterine göre yapılmış olup trendsiz model tercih edilmiştir.

Panel veri analizi, tek başına bir zaman serisi olarak ya da yatay kesit veriler kullanılarak oluşturulamayan karmaşık davranışsal modeller kurulmasına ve bu modellerin test edilmesine imkân vermesinden dolayı tercih edilmektedir (Yerdelen Tatoğlu, 2012, s.13). Bununla birlikte tipik bir panel, çok sayıda kesit birimi ve daha az zaman periyodu içermesinden dolayı kullanılan teknikler birimler arası bağlılığa ve heterojenliğe odaklanmaktadır (Greene, 2002, s.284). Panel verilerin kullanımı ile birlikte her bir birimde gözlenemeyen birim etkiler de ortaya çıkabilmektedir. Birim etkiler ile açıklayıcı değişken arasındaki korelasyon sıfıra eşitse tesadüfi etkiler, sıfırdan farklı ise de sabit etkiler modeli 
tercih edilmektedir (Yerdelen Tatoğlu, 2012, s.79). Söz konusu bu ilişkilerin incelenmesi ve hangi modelin kullanımının daha uygun olacağının sınanması için en çok kullanılan test Hausman testidir. Bu testte hem temel hem alternatif hipotez altında sabit etkiler modeli tutarlı iken, tesadüfi etkiler modeli temel hipotez altında etkin, alternatif hipotez altında ise tutarsızdır. Modele uygulanan Hausman test istatistiği 0.5942 olarak bulunmuştur. Bu durumda $\mathrm{H}_{0}$ hipotezi reddedilememiş ve tesadüfi etkiler modelinin etkin olduğu kabul edilmiştir. Kabul edilen tesadüfi etkiler modeline ait çıktı aşağıda tablo 4’te verilmiştir.

Tablo 4: Tesadüfi Etkiler Modeline Ait Çıktılar

\begin{tabular}{lcccccc}
\hline & Katsayı & Std. Err. & $\mathbf{Z}$ & $\mathbf{P}>|\mathbf{z}|$ & Gözlem & $\mathbf{2 2 8}$ \\
\hline ln_xm & -2.144239 & 1.549433 & -1.38 & 0.166 & Grup & 5 \\
ln_gdp & 4.418233 & 1.51114 & 2.92 & $0.003^{*}$ & Wald & 12.06 \\
& & & & & Chi2(2) & $(0.0024)$ \\
cons & -59.91556 & 22.89845 & -2.62 & $0.009^{*}$ & Hausman & 0.8473 \\
\hline
\end{tabular}

Bağımlı Değişken: Net Hata Noksan

*, \%1 anlamlılık düzeyinde bağımlı değişkeni açıklamakta anlamlıdır.

Wald testinin anlamlı olduğu yukarıdaki çıktı incelendiğinde gayri safi yurt içi hasılanın net hata noksan üzerine pozitif, ihracat ve ithalat rakamlarının toplamı olarak kabul edilen ticaret hacminin ise negatif etkisi olduğu görülmektedir.

Tablo 5: Tesadüfi Etkiler Modeline Ait Sınama Testleri

\begin{tabular}{lc}
\hline Levene, Brown ve Forsythe (4,190) & $\begin{array}{c}\text { W0 }=50.537363 \\
(0.00000000) *\end{array}$ \\
\cline { 2 - 2 } & $\mathrm{W}_{50}=48.302670$ \\
& $(0.00005837)^{*}$ \\
\hline BFN DW Ve Baltagi-Wu LBI & $\mathrm{W}_{10}=51.611102$ \\
& $(0.00000000)^{*}$ \\
\hline Langrange $(\mathrm{LM})$ ve Düzeltilmiş Langrage & $\mathrm{DW}=2.145479$ \\
\cline { 2 - 2 }$($ ALM) & Baltagi- Wu LBI $=2.1502883$ \\
\hline Friedman & LM (lambda=0) $(1)=0.3411$ \\
\hline *Prob $>$ F değeri & ALM (lambda $=0)(1)=0.4889$ \\
\hline
\end{tabular}

Varyansların eşitliğinin sınanması için kullanılmakta olan F testleri Gauss dağılımını temel almaktadır. Levene, 1960 yılında normal dağılım şartı sağlanmasa da kullanılabilecek dirençli bir test önermiştir. Levene tarafından önerilen bu test Brown ve Forsythe tarafindan 1974'te düzenlenmiş ve ortalama yerine kırpılmış ortalamaya dayalı alternatif yerel tahminciler önerilmiştir (Yerdelen Tatoğlu, 2012, s.222). Verilen tabloda $\mathrm{W}_{0}, \mathrm{~W}_{10}$ ve $\mathrm{W}_{50}$ olarak ifade edilen Levene, Brown ve Forsythe'nin test istatistikleri 4, 190 serbestlik derecesine sahip Snedecor F tablosu ile karşılaştırılmaktadır. Bu karşılaştırmada $\mathrm{H}_{0}$ hipotez olarak karşımıza çıkan birimlerin varyansları eşittir hipotezi reddedilmiştir. Modelde değişen 
varyans problemi vardır. Tesadüfi etkiler modelinde otokorelesyonun sınanması için kullanılan 1 serbestlik derecesine sahip LM ve ALM testi ki-kare dağılımına uygundur. Otokorelasyon sorunu yoktur şeklinde kurulan $\mathrm{H}_{0}$ hipotezi reddedilmiştir. Bhargava, Franzini ve Narendranathan tarafından önerilmiş olan DW testi ve Baltagi-Wu tarafından önerilen LBI test istatistikleri ise kritik eşik olarak kabul edilen 2 değerinin üzerindedir. Birimler arası korelasyonun sınanması için kullanın Friedman testi de yukarıda verilen tabloda yer almaktadır. Birimler arası korelasyonun varlığı, Friedman testine göre, $\mathrm{H}_{0}$ hipotezi reddedilememiştir. Birimler arası korelasyonun sınanmasında kullanılan Pesaran, Friedman ve Frees testlerinden sadece Friedman testi kullanılmıştır. Pesaran testinin küçük T ve büyün N durumunda geçerlilik göstermesi (Pesaran, 2014), Frees testinin ise normal dağılım göstermeyen verilerden kaynaklı olarak tutarsız sonuçlar vermesinden dolayı sadece Friedman testine yer verilmiştir. Sınaması yapılan modelde birimler arası korelasyonun varlığı kabul edilmiştir.

Ortaya çıkan değişen varyans ve birimler arası korelasyon sorununun çözümü için BeckKatz tahmincisi kullanılacaktır. Standart hataları değişen varyans ve birimler arası korelasyon sorununa karşı düzelten tahminciye ait çıktı aşağıda verilmiştir.

Tablo 6: Beck-Katz Tahmincisine Ait Çıktılar*

\begin{tabular}{|c|c|c|c|c|c|c|}
\hline & Katsayı & Std. Err. & $\mathbf{Z}$ & $\mathbf{P}>|\mathbf{z}|$ & Gözlem & 195 \\
\hline ln_xm & -3.186656 & 1.575366 & -2.02 & 0.043* & Grup & 5 \\
\hline $\ln _{-}$ & 3.139473 & 1.572999 & 2.00 & $0.046^{*}$ & $\begin{array}{c}\text { Wald } \\
\text { Chi2(2) }\end{array}$ & $5.98(0.050)$ \\
\hline
\end{tabular}

Yukarıdaki çıktıda değişen varyans ve birimler arası korelasyonun olduğu durumda kullanılmış olan dirençli tahmincide Wald testi anlamlıdır. Çıktı sonuçlarına baktığımızda; ithalat ve ihracat artışları toplamını oluşturan ticaret hacmi değişkeninde meydana gelen artışlar net hata noksan üzerine negatif bir etki yaparken, GDP artışları net hata noksanı pozitif yönde etkilemektedir. GDP' de meydana gelen \%1'lik bir değişim net hata noksan üzerinde yaklaşık 3 milyar \$ 'lık bir artış meydana getirirken, ticaret hacminde meydana gelen \%1'lik bir artış ise, net hata noksan üzerinde, yaklaşık olarak 3 milyar \$'lık bir azalışa sebep olmaktadir.

\section{Sonuç}

Ödemeler dengesinin amacı, bir ülkedeki tüm ekonomik aktörlerden gelen ticaret, hizmetler, transferler, fonlar ve finansal işlemlerin akışlarını diğer ülkelere karşı hesaplamaktır. Ödemeler Dengesi hesaplarındaki net hata ve noksanlar, kamuoyu tartışmalarında fazla dikkat çekmeyen ve çoğu zaman yanlış anlaşılan bir kalemdir. Öğenin adı, hataların ve verilerin 
uygun olmayan şekilde işlenmesini ima edecek şekilde yorumlanabilir, oysa bu kalem, ödemeler dengesi hesaplarını oluşturan birçok bireysel bileşenin istatistiksel anlamda çift girişli muhasebe sistemindeki bir tutarsızlığıdır. Teoride bir tutarsızlık olmamalıdır, ancak pratikte, net hatalar ve noksanlar, farklı ülkeler arasındaki akışların sisteme işlenmesindeki hataların miktar boyutlarını gösterir. Tutarsızlıkların nedenleri genellikle bilinmemekle birlikte, bazı durumlarda istatistiklerin gözden geçirilmesini gerektiren açıklamalar daha sonra ortaya çıkmaktadır. Zamanlama gecikmeleri, yetersiz kapsam veya metodolojik sorunlar dengesizliklere neden olabilir. Net hata ve noksan hesabının varlığının nedeni, yani kaynağının bulunmasıyla, ödemeler dengesi istatistiklerinin kalitesi daha da iyileştirilebilir.

Tüm ödemeler dengesi işlemleri ekonominin farklı alanlarına atıfta bulunur, farklı taraflara kaydedilir ve bu nedenle aynı işlemlere ilişkin veri kaynakları da farklıdır. Örneğin, mal işlemlerine ilişkin veriler, gümrük verileri (malların fiziksel akışı) ve bankalar tarafından sağlanan bu işlemler karşılığında ödenen para verileri bazında elde edilmektedir. Bunun için veri kaynakları iyi seçilmeli ve sorunlar yaşanmaması adına bu konuda yasalar ve cezai politikalar net bir şekilde belirtilmelidir. Buna ilaveten hataların ve noksanların hareketi, ekonomi politikasına yön verenler için önemli bir gösterge sayılabilir. Şöyle ki sınır ötesi kaçakçılıkların, turizm sektöründeki faaliyet sonuçlarının gerçek beyan edilmemiş olmasının, yasa dışı faaliyetlerin ve çeşitli vergi kaçakçılıkları gibi unsurların ülke ekonomisine zarar vereceğinden ötürü net hata noksan hesabı göstergeleri devletler içinde önemlidir. Yapılan bu çalışmada Dünya Bankası ve IMF uluslararası finans istatistiklerinden alınmış verilerle seçilmiş ülkelerde ithalat ve ihracat artışları toplamını oluşturan ticaret hacmi değişkeninde meydana gelen artışlar net hata noksan üzerinde negatif bir etki gösterdiği, GSYİH'nın ise söz konusu ülkelerde net hata noksanı pozitif yönde etkilediği sonucuna ulaşılmıştır. Sonuç olarak, ödemeler dengesindeki net hata ve noksan hesabının, sadece istatistik alanında değil, aynı zamanda ülkelerin uygulayacağı ya da uyguladıkları politikalar sonucunda ekonomilerinin durumu hakkında da önemli bir ekonomik gösterge olarak dikkate alınmasının gerekli olduğudur.

Hakem Değerlendirmesi: Dış bağımsız.

Çıkar Çatışması: Yazarlar çıkar çatışması beyan etmemişlerdir.

Finansal Destek: Yazarlar finansal destek beyan etmemişlerdir.

Peer-review: Externally peer-reviewed.

Conflict of Interest: The author has no conflict of interest to declare.

Grant Support: Authors declared no financial support.

\section{Kaynakça/References}

Adekunle, K.A. (2012). Errors and omissions and unrecorded capital flows and flight in Nigeria, International Journal of Business and Social Science, 3(3), 307-314. 
Alagöz, M. (2014). Ekonomik büyüme ve net hata-noksan ilişkisi: Türkiye üzerine ekonometrik bir uygulama. Gaziantep University Journal of Social Sciences, 13 (4), 881-888.

Barseghyan, M., \& Davtyan, A. (2018). Errors and omissions in Armenia's balance of payments: possible reasons and solutions. IFC: Central Bank of Statistics.

Bieganska, J. (2016). Saldo Bledow I Opuszczen W Bilansie Platniczym Polski. Wstęp Do Analizy, 3 (11), $186-196$.

Blomberg, G., Forss, L., \& Karlsson, I. (2003). Errors and omissions in the balance of payments statistics- a problem?, (Eds: Staffan Viotti \& Kerstin Mitlid , 41-50. http://www.riksbank.se/Upload/Dokument_riksbank/ Kat_publicerat/PoV_sve/sv/2003_2.pdf

Cencini A. (2005). World monetary discrepancies: A new macroeconomic analysis. Università della svizzera Italiana, Working Paper. https://www._World_Monetary_Discrepancies_A_New_Macroeconomic_Analysis/ link/03a39bf51e636a4298347c9b/download.

Committeri, M. (2000). Effects of volatile asset prices on balance of payments and international investment position data. IMF Working Paper, 191, 3-39.

Ding, S.L., \& Tang, T.C. (2017). Net errors and omissions' of balance of payments and its sustainability: a survey of literature. Economics Bulletin, 37(4), 2753-2766.

Duffy, M., \& Renton, A. (1971). An analysis of the U.K. balancing item. International Economic Review, 12(3), 448-464. https://doi.org/10.2307/2525357

Duman, K. (2004). Finansal krizlere karşı politika tercihleri. Akdeniz İ.̇.B.F. Dergisi, (8), 38-61.

Fausten, D. K., \& Brooks, R. D. (1996). The balancing item in Australia's balance of payments accounts: an impressionistic view. Applied Economics, 28(10), 1303-1311. https://doi.org/10.1080/000368496327859

Fausten, D. K., \& Pickett, B. (2004). 'Errors \& omissions' in the reporting of Australia's cross-border transactions. Australian Economic Paper, 43(1), 101-115. https:// doi.org/10.1111/j.1467-8454.2004.00219.x

Greene, W.H. (2002). Econometric analysis (Fifth Edition). New York: Prentice Hall.

Gujarati, D.N., \& Porter, D.C. (2012). Temel Ekonometri (Basic Econometrics) (Ü. Şenesen ve G.G. Şenesen, Çev.). İstanbul, Türkiye: Literatür Yayıncılık.

IMF Annual Report, https://www.imf.org/external/pubs/ft/ar/archive/pdf/ar1987.pdf. (22.12.2021)

International Financial Statistics (2021). https://data.imf.org/?sk=4c514d48-b6ba-49ed-8ab9-52b0c1a0179b (09.12.2021).

International Monetary Fund (1993).The Balance of Payments Manual, Washington: International Monetary Fund.

Jellema, T.R., Pastoris, F., \& Aguilar, C.P. (2020). Using synthetic indicators to assess the quality of macroeconomic statistics via mirror data, European Central Bank Statistics Paper, No. 34, 1-42. http://dx.doi.org/10.2866/4452

Kar, M. ve Kara, M.A. (2004).Gelişmekte olan ülkelere yönelik sermaye hareketleri ve krizler. Finans-Politik \& Ekonomik Yorumlar Dergisi, 41(481), 1-22.

Keşap, D. \& Sandalcılar, A. R. (2021). Net hata ve noksan hesabı belirleyicilerinin analizi: Türkiye örneği. Uluslararasi İktisadi ve İdari Incelemeler Dergisi, 32, 149-168.

Kilibarda, B. (2013). Net errors and omissions. Podgorica: Central Bank of Montenegro. Working Paper No 23, 7-45.

Kristinsson, T.Ö. (2016). Net errors and omissions in balance of payments statistics, impacts, causes and effects. ( Master's Thesis, Universidade Nova de Lisboa, Portugal). Retrieved from https://run.unl.pt/ bitstream/10362/19594/1/TEGI0370.pdf.

Lin, M.Y., \& Wang, H.H. (2009). What causes the volatility of the balancing item?. Economics Bulletin, 29(4), 2738-2748.

Pesaran, M.H. (2004). General diagnostic tests for cross section dependence in panels. Cambridge Working Papers in Economics, No.0435. 
Siranova M., Tiruneh M.W. \& Fisera B. (2020). Creating the illicit capital flows network in Europe - Do the net errors and omissions follow an economic pattern?, International Review of Economics and Finance ,1-50. ,https://doi.org/10.1016/j.iref.2020.10.020.

Siranova, M., \& Tiruneh, M. W. (2018). Exploding Net Errors and Omissions as a Capital Flight Phenomenon: The Case of Slovakia. Applied Economics, 50(16), 1866-1884.

Siranova, M., Tiruneh, M. W., \& Fisera, B. (2021). Creating the Illicit Capital Flows Network in Europe - Do the Net Errors and Omissions Follow an Economic Pattern?. International Review of Economics \& Finance, 71, 955-973.

Tang, T. C. (2006). Japan's balancing item: do timing errors matters?. Applied Economics Letters, 13(2), 81-87. https://doi.org/10.1080/13504850500378718

Tang, T. C. (2017). New perspective on the 'net error and ommision' in balance of payment accounts: An empirical study in Australia. Asian Academy of Management Journal of Accounting and Finance, 13(2), 27-44. https:// doi.org/10.21315/aamjaf2017.13.2.2

Taştan, S. (2015). Sustainability of balancing item of balance of payment for OECD countries: evidence from fourier unit root tests. Theoretical and Applied Economics, 22(3), 93-100.

TCMB (2002). Küreselleşmenin Türkiye ekonomisine etkileri, https://www.tcmb.gov.tr/wps/wcm/ connect/098cd40c-d8e3-4197, (10.12.2021).

Tombazos, C. G. (2003). New light on the 'impressionistic view' of the balancing item in Australia's balance of payments accounts. Applied Economics, 35(12), 1369-1378. https://doi.org/10.1080/0003684032000129354

Ünsal, E.M. (2005). Uluslararası iktisat teori, politika ve açık ekonomi makro iktisadı. Ankara : İmaj Yayıncılık.

Vuksic, G. (2009). Croatian balance of payments: Implications of net errors and omissions for economic policy. Institut Za Javne Financije- Newsletter, 41, 1-5.

Wang, J., \& Zivot, E. (2000). A bayesian time series model of multiple structural changes in level. Trend and Variance. Journal of Business and Statistics, 18, 374-386.

World Development Indicators (2021). https://data.worldbank.org/indicator/BN.KAC.EOMS.CD, (01.10.2021).

Yerdelen Tatoğlu, F. (2012). İleri panel veri analizi stata uygulamalı. İstanbul: Beta Yayıncılık. 